\title{
Contratos de opção: análise do potencial de sustentação de preços para o mercado de arroz
}

\author{
Andréia Cristina de Oliveira Adami* \\ Geraldo Sant'Ana de Camargo Barros** \\ Mirian Rumenos Piedade Bacchi***
}

Resumo: Um modelo econômico foi desenvolvido e aplicado para analisar o papel dos contratos de opção no mercado de arroz em casca como instrumento de estabilização de preço. O modelo baseia-se na alocação intertemporal das disponibilidades do produto durante determinado ano-safra de sorte a assegurar o desejado preço mínimo na safra e a evolução dos preços na entressafra que assegure o armazenamento competitivo. A possibilidade da complementação entre AGF e opções é explorada. Estimou-se que a probabilidade de os detentores das opções exercerem-nas é maior quando o Governo não contrata AGF. Conclui-se que os dois instrumentos podem ser utilizados de forma complementar, com a AGF elevando os preços de mercado no período da safra e os contratos de opção de venda garantindo que os preços sigam uma trajetória de armazenamento competitivo e reduzindo os riscos de preços futuros, ou seja, de adiar a venda para a entressafra.

\footnotetext{
*Doutoranda em Economia Aplicada pela Escola Superior de Agricultura "Luiz de Queiroz” - (ESALQ/USP). Email: Adami@esalq.usp.br

**Professor Titular do Departamento de Economia, Administração e Sociologia pela Escola Superior de Agricultura "Luiz de Queiroz" - (ESALQ/USP) e Coordenador Científico do CEPEA - Centro de Estudos Avançados em Economia Aplicada.

Email: gscbarro@esalq.usp.br

***Professora Livre-Docente na Escola Superior de Agricultura "Luiz de Queiroz" (ESALQ/USP). Email: mrpbacch@esalq.usp.br
} 
Palavras-chave: Opção de venda; Aquisições do Governo Federal; arroz em casca.

\section{Classificação JEL: Q18}

Abstract: An economic model was developed to analyze the put option contract role to stabilize prices in the paddy market. The possibility of using Federal Government Acquisitions (AGF) to complement the option instrument was considered. The role of the options was to reduce the risks of storing the product for later sale. The model is applied to analyze the option instrument implementation in the 2004/05 season. A two week demand for rice was estimated for the Brazilian market. The results show that the market prices go up when the government acts through the AGF. The options serve the purpose of making prices follow a compatible path. It was estimated that the probability for the option owners exercise their options is greater when the AGF are not used. One can conclude that these two tools (AGF and put options) can be used in a complementary way, with the AGF raising the market prices in the harvesting period, and the put option contracts making sure that the prices follow a competitive path and reduce the risks of future prices.

Key-words: Put option; Federal Government Acquisition; Paddy.

\section{JEL Classification: Q18}

\section{Introdução}

Com o objetivo de analisar o papel dos contratos de opção no mercado de arroz em casca como instrumento de estabilização de preço desenvolveu-se um modelo econômico que explica a alocação das disponibilidades de produto entre os períodos de safra e entressafra. As compras do Governo complementam a viabilização do preço mínimo. As opções teriam o papel de reduzir os riscos de adiar a venda para o período de entressafra. O modelo é aplicado para analisar a condução da política de preços do governo no ano-safra de 2005 .

Devido à importância do arroz como alimento básico para a popu- 
lação, o governo, a partir da década de 1960, tem adotado políticas de apoio à comercialização de forma a garantir renda ao produtor e abastecimento para a população.

O principal instrumento de intervenção governamental no mercado agrícola brasileiro é a Política de Garantia de Preços Mínimos (PGPM) que foi criada para dar sustentação aos preços recebidos pelo produtor nos períodos de oferta elevada. Da forma como foi desenhada, essa política de estoques reguladores fica sujeita a uma série de fatores que podem levá-la ao insucesso. Dentre estes fatores, Barros e Guimarães (1998) destacaram: a) falta de recursos para adquirir a quantidade necessária de produto, de forma a estabilizar os preços no patamar desejado; b) a dificuldade em realizar as compras no tempo necessário e, c) as dificuldades operacionais de manipulação do produto para transporte e armazenamento. À medida que o governo passou a operar mais ativamente nos mercados agrícolas criou-se um novo risco no mercado: a atuação dos órgãos estatais não necessariamente seguia a mesma regra que os operadores privados. O governo poderia adquirir ou vender estoques em ocasiões inadequadas para os agentes de mercado. Como resultado observou-se um afastamento do setor privado da comercialização, mormente na época de safra.

Na década de 1980, o Governo Federal chegou a adquirir através de compras diretas mais de $20 \%$ da produção de arroz. As aquisições do governo federal (AGF) chegaram a representar $27 \%$ da safra de 1986/87 e o financiamento da estocagem privada, através de empréstimo do governo federal (EGF), chegou a $30 \%$ da produção de arroz (REZENDE, 2003). Com o intuito de tornar a PGPM mais eficiente, a partir dos anos 1990, o governo vem reduzindo o volume de recursos gastos com a PGPM, diminuindo as operações de compras diretas e utilizando-se de contratos de opções.

Heifner, Wright e Plato (apud, BARROS, 2000) concluíram que os contratos de opções possibilitam ao produtor reduzir a incerteza quanto à renda na medida em que asseguram os preços e o escoamento de sua produção.

Os contratos de opções são mecanismos de formação de estoques pelos produtores dentro do ano-safra (estoca na safra para vender na entressafra) e, dessa forma, visam a sustentar os preços ao produtor 
dentro do ano e devem ser avaliados quanto ao seu potencial de sinalização dos preços de mercado e aumento de segurança ao produtor.

\section{Metodologia}

O modelo utilizado está baseado no modelo teórico desenvolvido por Bressler e King (1970) e adaptado por Barros (2005). Esse modelo ilustra o equilíbrio no mercado de estoques para 2 períodos sob competição perfeita.

A Figura 1 mostra o equilíbrio no mercado considerando-se que o ano-safra divide-se em dois períodos: safra e entressafra, os custos de armazenamento $(\mathrm{C}=\mathrm{s})$ e demandas iguais para os dois períodos. Se o preço mínimo adotado pelo governo corresponder ao preço de equilíbrio de mercado na safra $\left(\mathrm{P}_{1}^{*}\right)$ e o preço de exercício da opção corresponder ao preço mínimo mais os custos de armazenagem do produto até a entressafra tem-se o preço esperado para a entressafra, $\mathrm{P}_{2}{ }^{*}$. Assim, o preço mínimo funciona como sinalizador do equilíbrio de mercado.

Figura 1. Equilíbrio no mercado do produto para dois períodos safra e entressafra.

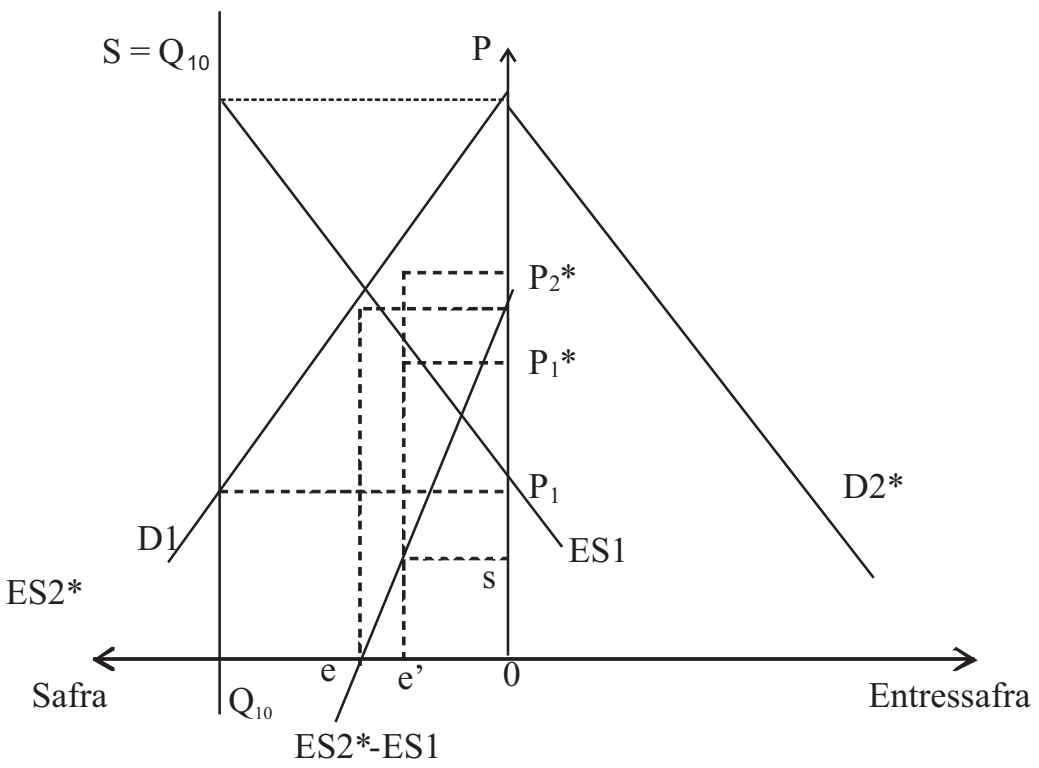

RER, Rio de Janeiro, vol. 46, no 01, p. 229-247, jan/mar 2008 - Impressa em abril 2008 
O problema será resolvido assumindo-se as seguintes condições de equilíbrio:

$$
\begin{aligned}
& \mathrm{S}=\mathrm{Q}_{1}{ }^{S}=\mathrm{Q}_{10} \\
& \mathrm{D} 1=\mathrm{Q}_{1}{ }^{\mathrm{d}}=\alpha_{1}-\beta_{1} \mathrm{P}_{1} \\
& Q_{2}{ }^{S}=0 \\
& \mathrm{D} 2^{*}=\mathrm{Q}_{2}{ }^{\mathrm{d}}=\alpha_{2}-\beta_{2} \mathrm{P}_{2}
\end{aligned}
$$

Onde $\mathrm{Q}_{1}{ }^{\mathrm{s}}$ é a quantidade ofertada na safra, $\mathrm{Q}_{10}$ é a produção anual e $\mathrm{Q}_{1}{ }^{\mathrm{d}}$ é a quantidade demandada no período 1- safra. $\mathrm{Q}_{2}{ }^{\mathrm{s}}$ a quantidade produzida na entressafra e $\mathrm{Q}_{2}{ }^{\mathrm{d}}$ a demanda para o período 2, ou seja, é a quantidade demandada na entressafra que é idêntica à $\mathrm{Q}_{1}{ }^{\mathrm{d}}$.

Respeitando-se as condições de equilíbrio e considerando-se armazenamento com custo: $\mathrm{C} \geq \mathrm{P}_{2}-\mathrm{P}_{1}$, pode-se obter as curvas de excesso de oferta, onde $\mathrm{Y}$ é o excesso de oferta para na safra (ES1) e X o excesso de demanda na entressafra $\left(-E S 2^{*}\right)$.

$$
\begin{aligned}
& Y=Q_{1}{ }^{S}-Q_{1}{ }^{d}=Q_{10}-\left(\alpha_{1}-\beta_{1} P_{1}\right) \\
& P_{1}^{*}=\frac{Y-Q_{10}+\alpha_{1}}{\beta_{1}} \\
& X=Q_{2}{ }^{S}-Q_{2}{ }^{d}=0-\left(\alpha_{2}-\beta_{2} P_{2}\right) \\
& P_{2}{ }^{*}=\frac{X+\alpha_{2}}{\beta_{2}}
\end{aligned}
$$

Em equilíbrio, considerando-se as restrições:

$-\mathrm{X}=\mathrm{Y}=\mathrm{Z}$

$\mathrm{P}_{2}{ }^{*}-\mathrm{P}_{1}{ }^{*}=\mathrm{C}$

Tem-se que: $Z=-\frac{\left(\beta_{1} \beta_{2}\right)}{\left(\beta_{1}+\beta_{2}\right)} C+\left[\frac{\left(Q_{10}-\alpha_{1}\right)}{\beta_{1}}+\frac{\alpha_{2}}{\beta_{2}}\right] \frac{\beta_{1} \beta_{2}}{\left(\beta_{1}+\beta_{2}\right)}$.

Sendo $Z$ a quantidade que deve ser armazenada na safra para voltar 
ao mercado na entressafra, considerando-se os custos de armazenamento e a produção do ano safra.

O governo lançará contratos de opção no período da colheita assegurando um preço minimamente remunerador na entressafra (preço de exercício $=P_{2}{ }^{*}$ ). A expectativa é que, sendo o preço de exercício equivalente ao preço de mercado na safra acrescido dos custos de armazenagem, os produtores estejam interessados em adquirir opções que seriam um fator de segurança para armazenagem.

O governo deve lançar contratos de opção de venda com preços de exercício que correspondam ao preço de equilíbrio, de sorte que os contratos correspondam à quantidade Oe'. Deve determinar o preço de exercício (Pe) ao nível de $\mathrm{P}_{2}{ }^{*}$, que é o preço de equilíbrio de mercado esperado para a entressafra.

Caso o governo determine um preço de exercício abaixo de $\mathrm{P}_{2}{ }^{*}$, os produtores não se incentivarão a contratar as opções, pois o preço de exercício não cobrirá o preço corrente na safra mais os custos de carregar o produto até a entressafra, e, portanto, a atuação através dos contratos de opção não se efetivará, sendo necessário retirar o volume Oe' do mercado através de AGF para dar sustentação aos preços.

Embora teoricamente se espere que, face à colocação de um montante adequado de opções de venda o preço da safra se eleve ao nível mínimo desejado, permanece a dúvida quanto a se, nas condições específicas de mercado - raramente primando pela efetiva concorrência e freqüentemente marcada pela escassez de capital - os produtores poderiam vir a ter que realizar vendas abaixo do preço para terceiros, que, estes sim, se beneficiariam das opções de venda. Para contornar essa situação é recomendado que sejam realizadas operações de AGF, na época da safra, para elevar os preços ao patamar mínimo desejado - como pode ser visualizado na Figura 2 - e com as opções garantindo que os preços sigam trajetória compatível com o armazenamento competitivo.

A Figura 2 mostra a alteração no equilíbrio de mercado quando o governo retira a quantidade $G$ através de operações de AGF de forma a elevar os preços no período da safra. Ao retirar a quantidade $G$ do mercado o governo reduz a oferta no ano safra provocando um aumento dos preços. 
Figura 2. Equilíbrio no mercado do produto após redução da oferta através das operações de AGF

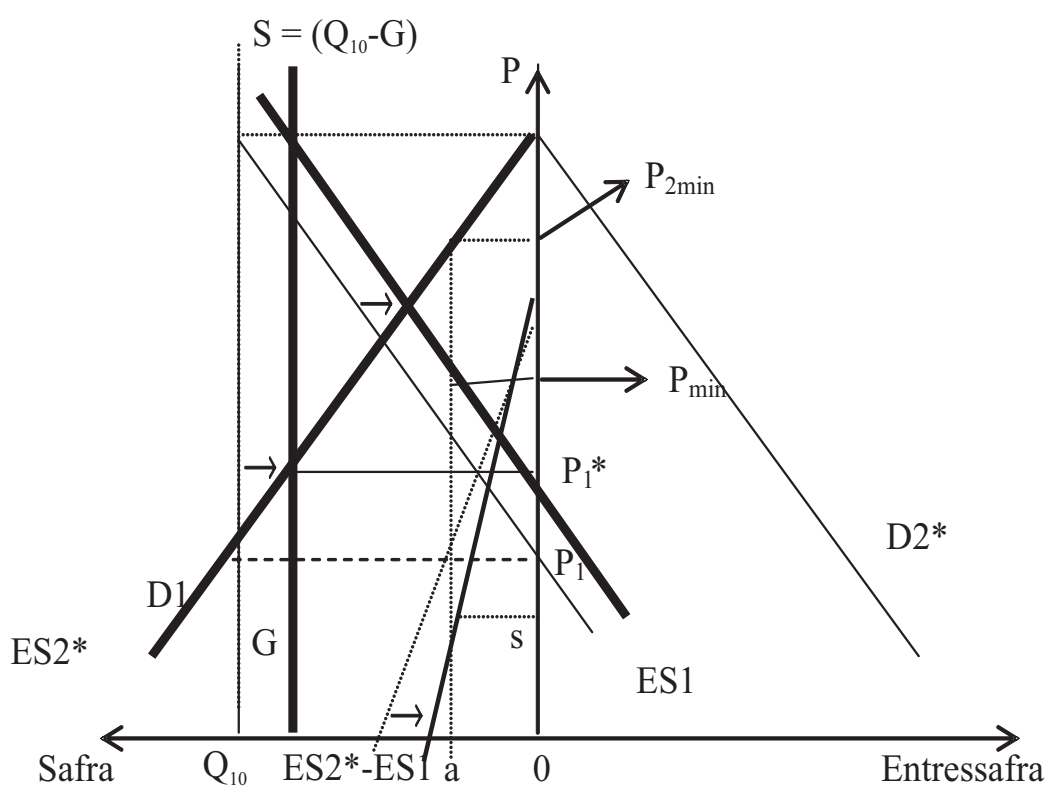

Ao novo equilíbrio, $\mathrm{P}_{\min }$ será o preço na safra e $\mathrm{P}_{2 \min }$ será o preço na entressafra e, a diferença entre os preços é dada pelo custo de armazenamento (s). O volume armazenado de um período para outro será Oa.

Considerando-se as retiradas de produto do mercado por meio de AGF para dar sustentação aos preços, tem-se a quantidade a ser retirada do mercado $G$ e novos preços de equilíbrio de mercado: $P_{\min }$ e $P_{2 \min }$.

Ao novo equilíbrio $Z$ será dada pela equação (11) e $G$ (volume de AGF) pela (12):

$$
\begin{aligned}
& Z=\frac{\alpha_{2} \beta_{1}-\alpha_{1} \beta_{2}}{\beta_{1}+\beta_{2}}+\frac{\beta_{2}}{\beta_{1}+\beta_{2}}\left(Q_{10}-G\right)-\frac{\beta_{1} \beta_{2} C}{\beta_{1}+\beta_{2}} \\
& G=\left(\beta_{1}+\beta_{2}\right) P_{\min }+\beta_{2} C+Q_{10}-\left(\alpha_{1}+\alpha_{2}\right)
\end{aligned}
$$

Portanto: $\mathrm{G} \geq 0$ se $\mathrm{P}_{\min } \geq \frac{\left(\alpha_{1}+\alpha_{2}\right)-Q_{10}+\beta_{2} C}{\beta_{1}+\beta_{2}}$. 
A quantidade retirada do mercado por meio de AGF não deve retornar ao mercado no mesmo ano safra para não alterar os preços de equilíbrio dentro do ano. Pode-se verificar que o instrumento AGF deve ser utilizado de forma complementar aos contratos de opção ou quando os preços de equilíbrio, utilizando-se o instrumento de opção, ficarem abaixo dos preços que o governo deseja assegurar.

Para que haja equilíbrio no mercado durante o ano e os preços sejam assegurados é de fundamental importância que o governo determine com precisão os preços mínimos e de exercício dos contratos de opção. Para que o equilíbrio ocorra o governo deve determinar as quantidades que devem permanecer no mercado durante a safra e entressafra e, se necessário retirar, no início do ano safra, quantidades excedentes através de operações com AGF.

O governo quando atua no mercado através do instrumento de opções deve determinar, na época do plantio, o preço mínimo que prevalecerá durante a safra, pois é nesse período que os produtores tomam a decisão quanto à viabilidade da área a ser plantada.

Durante a safra o governo deverá disponibilizar uma quantidade de contratos de opção que corresponda à quantidade de produto que deverá ser retirada do mercado no período da safra para garantir o suprimento do produto na entressafra e garantir a sustentação dos preços na safra, além de determinar o preço para o período da entressafra que será o preço de exercício da opção.

No caso da opção pública, o governo deve disponibilizar a quantidade de contratos correspondente à quantidade Oa, na Figura 2, que é a quantidade que deverá ser retirada do mercado no período da safra para voltar na entressafra e ter disponível os recursos necessários para o exercício de todas as opções. Se optar pelas opções privadas, deverá disponibilizar a quantidade de contratos referentes à quantidade Oa a ser retirada do mercado na safra, porém a quantidade de recursos a disponibilizar será menor, ou seja, correspondente a diferença entre o preço de mercado à época da entressafra e o preço de exercício da opção. Mas, pode ser que nem toda quantidade de contratos de prêmio de risco seja adquirida pelas indústrias e ou comerciantes, caso não ocorra a venda de todos os contratos a diferença entre os contratos vendidos e a quantidade Oa deve ser retirada pelo governo por meio de opções públicas. 
Os produtores diante da oferta dos contratos de opção de venda avaliarão se o preço de exercício (Pe) cobre o preço de mercado na safra mais os custos de armazenar o produto para a entressafra. Se o preço de exercício estiver abaixo do preço de equilíbrio na entressafra $\left(\mathrm{P}_{2}{ }^{*}\right)$ não haverá demanda por parte dos produtores com relação aos contratos de opção e, assim, os produtores desejarão aumentar a oferta durante o período de safra, o que acarretará redução ainda maior de preços na safra. Assim, a determinação, por parte do governo, do preço mínimo e do preço de exercício é essencial para que haja sustentação dos preços no mercado. Qualquer diferença entre os preços mínimos e de exercício com os preços de equilíbrio de mercado poderá inviabilizar a sustentação dos preços através desses mecanismos.

Deve-se considerar também a possibilidade de importação do produto e o impacto da quantidade importada sobre os preços de mercado. Para o caso do arroz em casca, de acordo com a CONAB (2005b), sabese que a Argentina e o Uruguai plantam arroz para vender ao Brasil. Essa quantidade importada entra no mercado brasileiro pressionando os preços no mercado interno e gerando estoque do produto, prejudicando a comercialização da safra brasileira.

Figura 3. Equilíbrio no mercado do produto considerando-se importações.

$$
\mathrm{S}=\left(\mathrm{Q}_{10}+\mathrm{I}\right)
$$

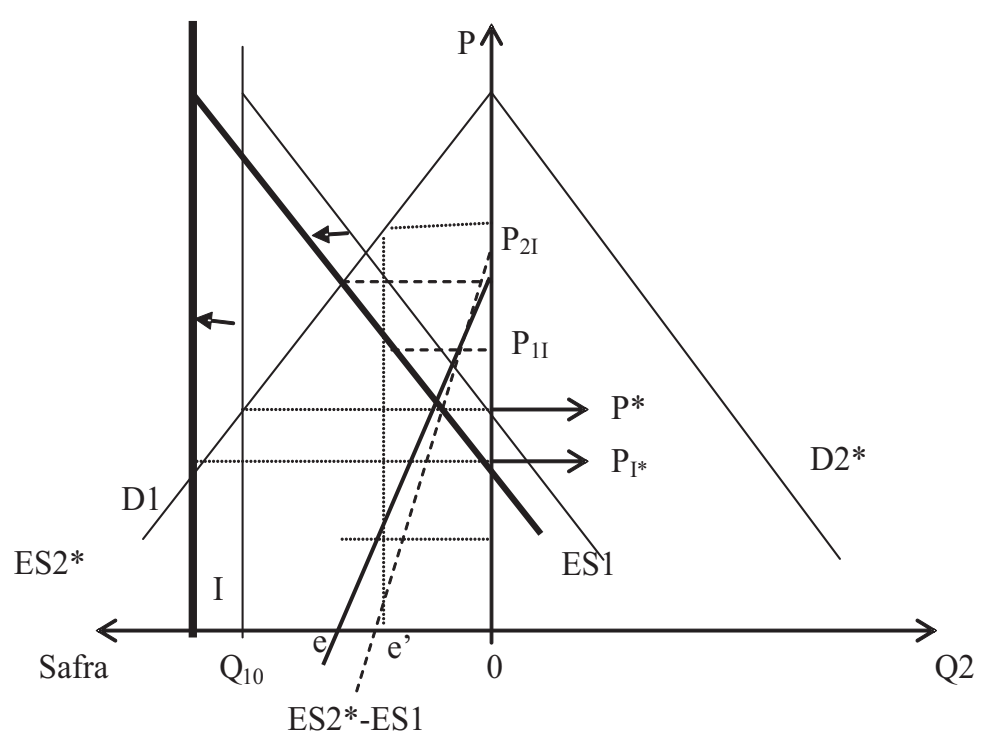

RER, Rio de Janeiro, vol. 46, no 01, p. 229-247, jan/mar 2008 - Impressa em abril 2008 
A Figura 3 mostra a alteração no equilíbrio de mercado quando existe comércio do produto entre países. A quantidade I entra no mercado através das relações comerciais internacionais de forma a reduzir os preços no período da safra. Ao importar a quantidade I os comerciantes aumentam a oferta do produto no ano safra provocando uma queda nos preços de mercado. Ao novo equilíbrio $\mathrm{P}_{\mathrm{I}^{*}}$ será menor que $\mathrm{P}^{*}$

Pode-se relacionar a quantidade I a ser importada com os preços de equilíbrio de mercado. Assim, a quantidade a ser importada no ano safra é dada por I e a quantidade a ser estocada para a entressafra é dada por Z.

$$
Z=\frac{\alpha_{2} \beta_{1}-\alpha_{1} \beta_{2}}{\beta_{1}+\beta_{2}}+\frac{\beta_{2}\left(Q_{10}+I\right)}{\beta_{1}+\beta_{2}}-\frac{\beta_{1} \beta_{2} C}{\beta_{1}+\beta_{2}}
$$

Resolvendo para $\mathrm{P}_{1 \mathrm{I}}$ tem-se a equação (14):

$$
P_{1 I}=\frac{\left(\alpha_{1}+\alpha_{2}\right)-\beta_{2} C-Q_{10}-I}{\beta_{1}+\beta_{2}}
$$

Ou seja, o preço de mercado tende a cair com as importações.

Além disso, considerando-se a aplicação de uma política de preço mínimo, tem-se pela equação (15) que:

$$
\left(Q_{10}+I-G\right)-\left(\alpha_{1}-\beta_{1} P_{\operatorname{Im} \text { in }}\right)=\alpha_{2}-\beta_{2}\left(P_{\operatorname{Im} \text { in }}+C\right)
$$

Logo: $P_{\min }=\frac{\left(\alpha_{1}+\alpha_{2}\right)-\beta_{2} C-\left(Q_{10}+I-G\right)}{\beta_{1}+\beta_{2}}$.

Indicando que, para sustentar determinado preço mínimo, o mercado poderá ter que contar com um maior volume de AGF para conter o impacto das importações.

\subsection{Fonte de dados}

Para a determinação da oferta anual foram utilizados os dados de estoques, produção e AGF procedentes da Companhia Nacional de Abastecimento (CONAB, 2005c). 
A função de demanda inversa anual foi definida após aplicar testes de estacionariedade e causalidade. Após definida a função, utilizou-se dados referentes aos preços do produto, consumo aparente per capita e renda per capita para estimá-la. Os valores referentes ao preço do arroz e renda (Produto Interno Bruto - PIB) foram deflacionados pelo Índice Geral de Preços-Disponibilidade Interna (IGP - DI) divulgado pela Fundação Getúlio Vargas a preços de 2004.

O preço do arroz utilizado foi o preço do arroz em casca ao produtor médio nacional divulgado pela Fundação Getúlio Vargas/Agroanalysis (Instituto de Pesquisa Econômica Aplicada - IPEA, 2005).

O consumo considerado foi o consumo aparente divulgado pela CONAB (2005c).

A forma de demanda inversa que melhor se ajustou foi a demanda inversa linear. A partir da demanda inversa anual estimada pôde-se derivar as demandas quinzenais para o mercado do arroz em casca que consta da equação (16):

$$
P i=5,26-1,5529 \times C i
$$

Sendo Pi o preço do quilo do arroz em casca e Ci o consumo per capita.

O custo de armazenamento foi calculado com base na Tabela de Tarifas para Unidades Armazenadoras de Ambiente Natural da CONAB de fevereiro de 2005 (CONAB, 2005a). O resultado consta da equação (17) a seguir:

$$
\left.C A=0,00333+\left[0,00872+(0,00915) P_{1}\right)\right] \times s
$$

Onde $\mathrm{s}=\mathrm{t}-1$, representa o período de tempo de armazenamento, ou seja, o número de quinzenas que o arroz em casca fica estocado.

O preço mínimo calculado, média nacional, para o ano de 2005 foi de $\mathrm{R} \$ 0,313$ o quilo do arroz em casca.

Considerou-se o preço de paridade de importação, média quinzenal, divulgado pela CONAB (2005b), para o ano de 2005, que decompõe o preço de importação até o produtor. 


\section{Resultados e discussão}

Para o ano de 2005 a CONAB (2005d) divulgou uma previsão de safra de $12.809,4$ mil toneladas de arroz em casca e estoque inicial de 1.576,6 mil toneladas, sendo o consumo previsto de 12.830,0 mil toneladas de arroz em casca. Não foram realizadas operações de AGF no início da safra.

Para calcular a demanda agregada considerou-se a população total residente no Brasil no ano 2005 que foi de 184.863.645 habitantes (FUNDAÇÃO INSTITUTO BRASILEIRO DE GEOGRAFIA E ESTATÍSTICA - IBGE, 2005). E assim, a função de demanda agregada quinzenal é dada pela equação (18) a seguir:

$$
C i=626687757-119052187 \times P i
$$

De posse da oferta prevista para 2005 e da função de demanda quinzenal resolveu-se o problema para o equilíbrio dentro do ano safra determinando primeiramente $\mathrm{P}_{1}$, em seguida obteve-se os demais preços quinzenais do quilo de arroz em casca pela relação entre os preços e o custo de armazenamento considerando-se a função de custo de armazenamento.

Assim, em equilíbrio:

$$
P t=P_{1}+C A t=P_{1}+0,00333+\left[0,00872+(0,00915) P_{1}\right] \times s
$$

Os preços de equilíbrio calculados através da aplicação do modelo para os dados do mercado de arroz em casca no ano de 2005, os preços de importação e preços de exercício das opções constam da Figura 4.

Na Figura 4 as quinzenas 1, 2, 3 e 4 são referentes às quinzenas dos meses de janeiro e fevereiro de 2005 , período de entressafra. A quinzena 5 é a primeira quinzena do mês de março de 2005, início da safra, o que explica a mudança no comportamento dos preços nesse período.

Pode-se observar que sem a intervenção do governo através de aquisições de arroz em casca, o menor preço será $\mathrm{R} \$ 0,114 / \mathrm{kg}$, média nacional, e os outros preços seguem comportamento de armazenamento competitivo (preço inicial mais custos de armazenagem quinzenal). Nesse cenário verifica-se que os preços de exercício das opções (que foram 
de 0,539 e 0,479 ) estão muito superiores à média de mercado, mesmo descontando os custos de armazenagem do período de exercício à contratação da opção. Os preços de importação encontram-se fora da região que considera os preços observados com $95 \%$ de probabilidade (limites superior e inferior), ou seja, estão superiores aos preços de mercado mais dois desvios, da quinta quinzena de 2005 até a $17^{\text {a }}$ quinzena.

Figura 4. Preços mercado arroz em casca - sem AGF

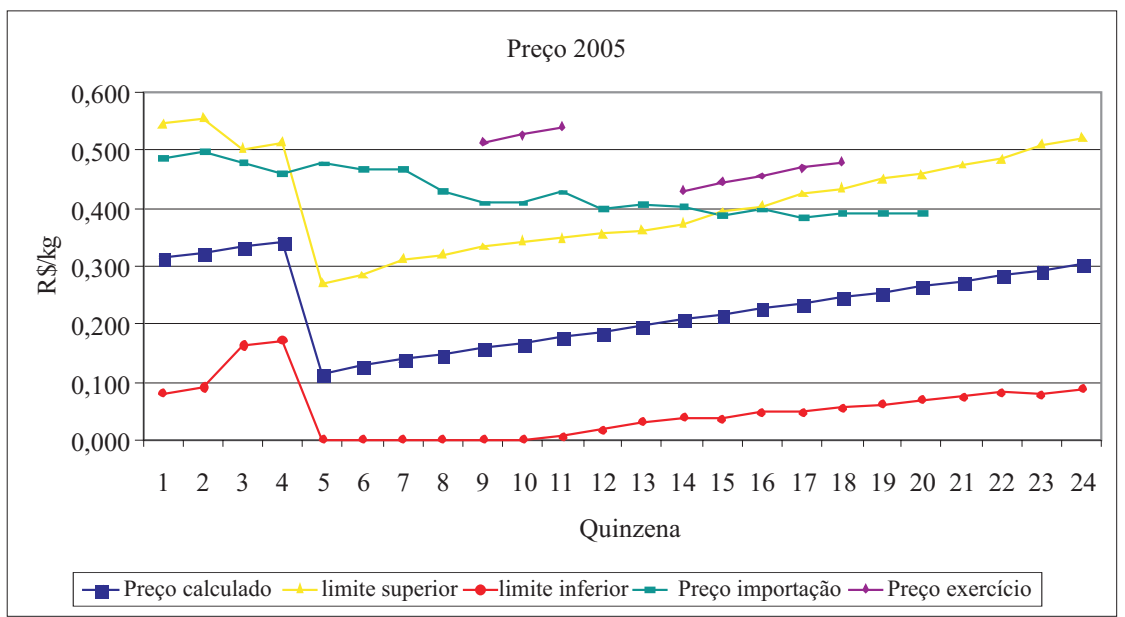

Figura 5. Armazenagem arroz em casca - Sem intervenção Mercado

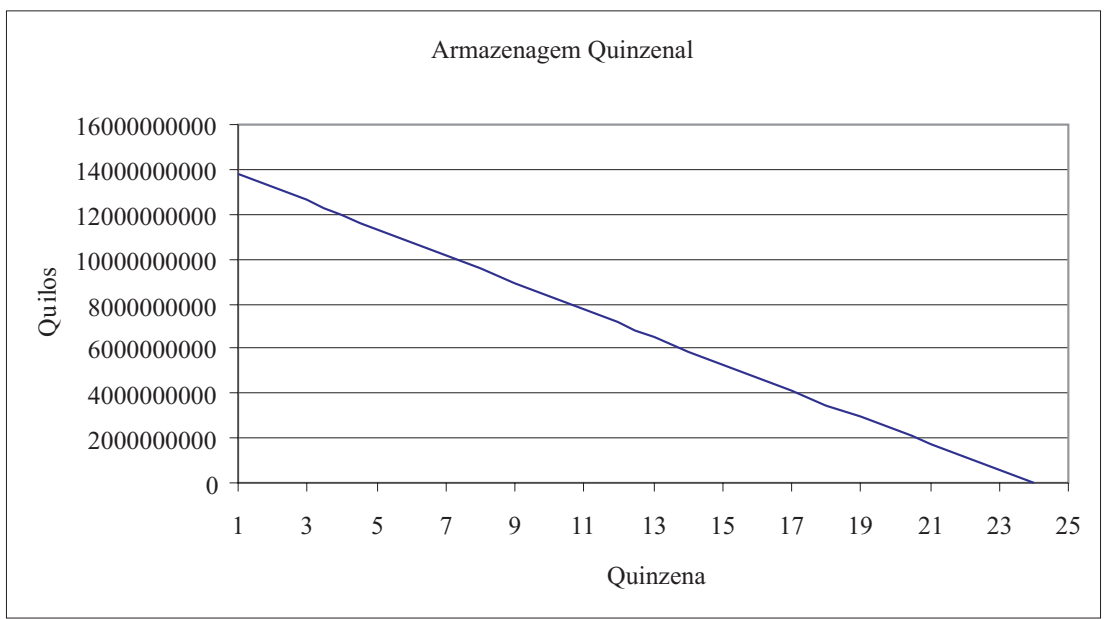

RER, Rio de Janeiro, vol. 46, no 01, p. 229-247, jan/mar 2008 - Impressa em abril 2008 
A Figura 5 mostra a evolução quinzenal da armazenagem do arroz em casca- que é a diferença entre a oferta total no ano e o consumo quinzenal - considerando-se que não haja intervenção do governo.

O preço de equilíbrio de mercado $\mathrm{R} \$ 0,114 / \mathrm{kg}$ é muito inferior ao preço mínimo que o Governo deseja assegurar ao produtor de arroz em casca. Para assegurar o preço mínimo de $\mathrm{R} \$ 0,313 / \mathrm{kg}$, média nacional, o Governo teria que retirar do mercado 629 mil toneladas de arroz em casca - valor calculado através da aplicação do modelo - através de operações de AGF. A partir do preço mínimo os preços de mercado são acrescidos do custo de armazenamento. Após a intervenção no mercado o preço mínimo $\left(\mathrm{P}_{1}=\mathrm{R} \$ 0,313\right)$ é assegurado e, considerando-se os custos de estocagem quinzenais, a trajetória de alta dos preços de mercado pode ser visualizada na Figura 6.

Figura 6. Preços de mercado após AGF

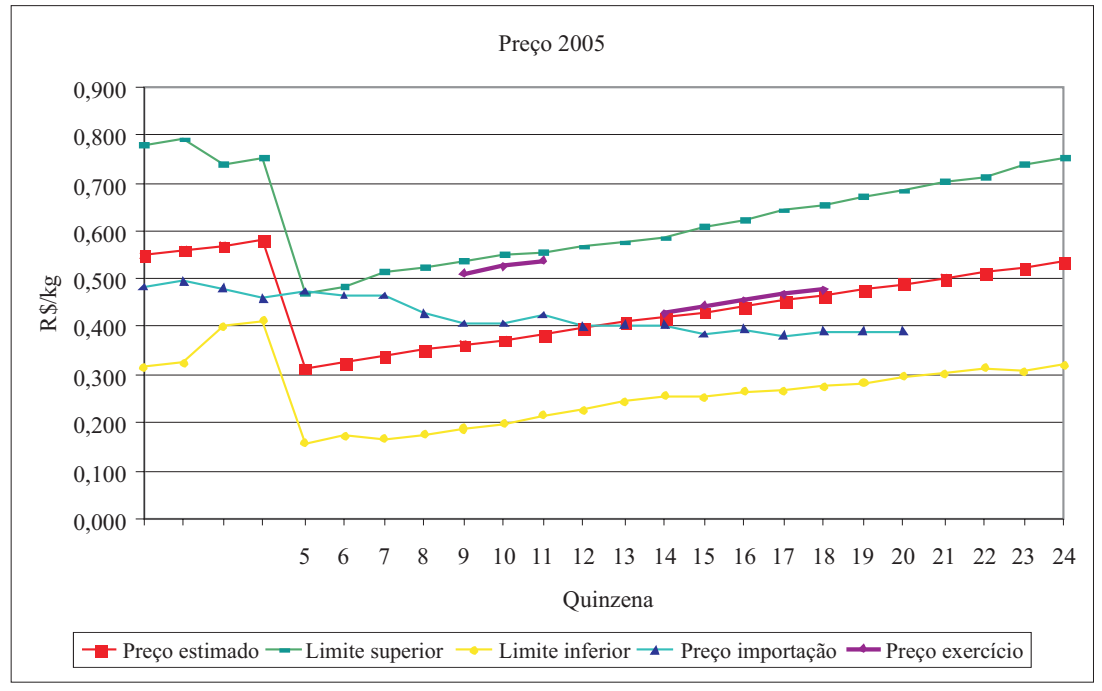

Como o Governo reduziu a oferta no ano-safra, a menor disponibilidade do produto acarretará em menores quantidades a serem armazenadas quinzenalmente, conforme mostra-se na Figura 7: 
Figura 7. Armazenagem arroz em casca após AGF

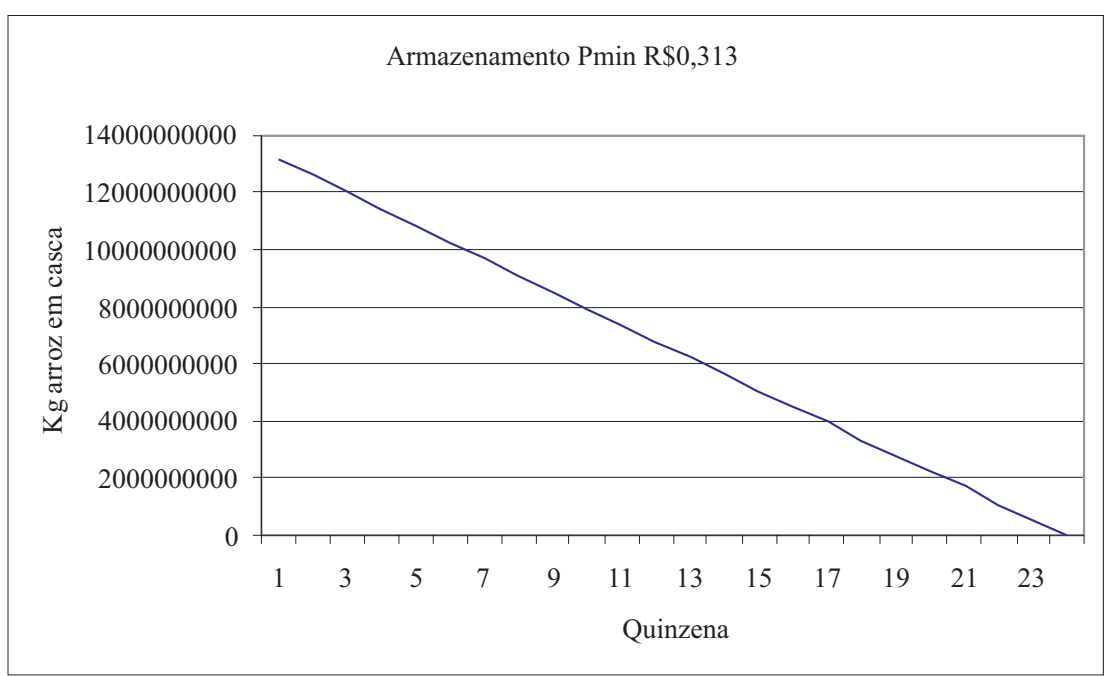

Num cenário sem intervenção governamental (Figura 6) verifica-se que os preços de exercício das opções estão muito superiores à média de mercado, mesmo descontando os custos de armazenagem do período de exercício à contratação da opção. Os preços de importação encontram-se fora da região que considera os preços observados com $95 \%$ de probabilidade, ou seja, estão superiores aos preços de mercado mais dois desvios, da quinta quinzena de 2005 até a $17^{\text {a }}$ quinzena.

É interessante observar na Figura 7 que, quando o governo atua promovendo compras diretas os preços de mercado aumentam.

Os preços de importação no cenário anterior (Figura 6) ficavam fora da área que delimita a região onde $95 \%$ dos preços de mercado são observados no período da safra (quinzenas de 5 a 17), ou seja, havia maior viabilidade de importador arroz em casca no período da entressafra. A intervenção do governo passa, no novo cenário (Figura 7), a viabilizar a importação de arroz o ano todo devido aos maiores preços de mercado.

Os preços de exercício na situação anterior (Figura 6) estavam muito superiores aos valores encontrados, mesmo considerando dois desvios com relação à média. Quando há intervenção e os preços se elevam os preços de exercício passam a estar dentro de região possível, assim, a operação de AGF torna os altos preços de exercício viáveis. 
A probabilidade de exercício das opções com vencimento para junho, num cenário onde não há intervenção no mercado e preço de exercício $\mathrm{R} \$ 0,539$ é de quase $100 \%$, ou seja, considerando-se os preços calculados e o intervalo determinado pelos desvios, é praticamente certo que os produtores exerceriam suas opções.

Já, para as opções com vencimento para junho, num cenário com intervenção para garantir o preço mínimo e preço de exercício $\mathrm{R} \$ 0,539$, a probabilidade de exercício das opções é de aproximadamente $95 \%$.

Considerando-se as opções com vencimento para a primeira quinzena do mês de setembro/2005 ao preço de exercício de $\mathrm{R} \$ 0,479$ e sem intervenção a probabilidade de exercício é de 99,5\% e com intervenção para garantir o preço mínimo a probabilidade é de aproximadamente $10 \%$.

No caso das opções com vencimento para a segunda quinzena do mês de setembro/2005 ao preço de exercício de $\mathrm{R} \$ 0,479$ e sem intervenção a probabilidade de exercício é de 99,3\% e com intervenção para garantir o preço mínimo a probabilidade é de aproximadamente $5 \%$.

Através da análise dos preços e das probabilidades de exercício das opções pode-se verificar que quando o governo participa do mercado promovendo operações de AGF a probabilidade de exercício das opções é menor, pois os preços de mercado são maiores. Porém preços maiores no mercado viabilizarão internalizar uma quantidade maior de importações, o que causa uma pressão maior sobre os preços e sobre o governo para que o mesmo disponibilize compras diretas.

Através dos resultados dos leilões pode-se verificar que foram lançadas opções de arroz na primeira e segunda quinzena de maio para vencimento na primeira quinzena do mês de junho/2005. O preço de exercício foi de $\mathrm{R} \$ 0,539 / \mathrm{kg}$. Descontando-se os custos de armazenagem da opção lançada na primeira quinzena de maio o preço equivaleria na época do lançamento do contrato privado da opção de venda à $\mathrm{R} \$ 0,512$ e $\mathrm{R} \$ 0,527$ na segunda quinzena e, os preços de mercado observados nesses vencimentos, para o Estado do Rio Grande do Sul (CONAB, 2005a) onde foram lançadas as opções, foi de $\mathrm{R} \$ 0,405$ na primeira quinzena do mês de maio, $\mathrm{R} \$ 0,400$ segunda quinzena de maio e $\mathrm{R} \$ 0,410$ na primeira quinzena de junho/2005.

As opções de julho e agosto de 2005 foram lançadas com um preço de exercício de $\mathrm{R} \$ 0,479 / \mathrm{kg}$. Descontando os custos de armazena- 
mento esse preço equivaleria à época do lançamento a $\mathrm{R} \$ 0,428$ na segunda quinzena de julho, 0,443 na primeira quinzena de agosto, 0,455 na segunda quinzena de agosto e 0,467 na primeira semana se setembro/2005. Os preços de mercado, para o Estado do Rio Grande do Sul, à época do lançamento das opções eram: $\mathrm{R} \$ 0,39$ na segunda quinzena de julho, $\mathrm{R} \$ 0,37$ na primeira quinzena de agosto, $\mathrm{R} \$ 0,36$ na segunda quinzena de agosto, $\mathrm{R} \$ 0,354$ na primeira quinzena de setembro e $\mathrm{R} \$ 0,353$ na segunda quinzena de setembro. Assim, as opções lançadas em 2005 estavam muito atrativas para seus portadores com grandes chances de serem exercidas.

\section{Conclusão}

Em 2005, o preço de exercício dos contratos de opção esteve muito superior ao preço mínimo estipulado pelo Governo e superior, também, aos preços de mercado. O preço de exercício foi definido considerandose os preços de mercado dos anos anteriores e não os custos de produção do arroz em casca ou o preço mínimo. Dessa forma, com um preço de exercício maior que os preços de mercado houve pouco interesse por parte dos comerciantes e indústrias beneficiadoras de arroz, de um lado, e muito interesse por parte dos produtores de outro. Houve, também, dificuldade em saber qual o preço que o Governo desejava assegurar.

Quanto às opções de venda pode-se concluir que, para o produtor, o resultado é o mesmo tanto contratando opções privadas quanto opções públicas. A diferença está na operacionalização dos contratos, que se dá por operadores privados, no caso das opções privadas de venda e, pelo Governo, no caso das opções de venda públicas.

O Governo tem maior autonomia operando através das opções de venda públicas, pois, através dos leilões de opção de venda pública tem um relacionamento direto com os produtores rurais. Por outro lado, o custo de se utilizar as opções públicas é muito maior, pois nesse caso, o Governo deve ter assegurado em seu orçamento um volume de recursos necessário para o exercício de todos os contratos de opção de venda negociados nos leilões.

O custo de operar através das opções privadas é menor para o Governo, pois terá que pagar apenas a diferença entre os preços de exercício 
da opção de venda e o preço de mercado no vencimento do contrato. Os contratos de opção de venda privados também são um importante instrumento de incentivo à armazenagem privada dentro do ano e podem melhorar o relacionamento entre produtores e beneficiadores da cadeia do arroz.

Os contratos de opção de venda, tanto público como privados, têm um importante papel na redução do risco da retenção da produção após a safra. À medida que se faz necessário o armazenamento de parte da produção para a entressafra para assegurar o abastecimento, os contratos de opção de venda podem dar uma sinalização mais correta dos preços futuros, garantindo que os preços sigam uma trajetória compatível com o armazenamento competitivo.

Portanto, espera-se que, se o Governo disponibilizar um número adequado de contratos no período adequado e, complementarmente utilizar operações de AGF, se necessário, também em período adequado - logo no início da safra para elevar os preços de mercado - os preços ao produtor estejam assegurados no patamar desejado.

Quanto às operações de AGF, em 2005, o Governo não disponibilizou as compras para o setor em tempo hábil. As compras diretas começaram no final da safra, no final de setembro/2005, quando os preços já tinham se reduzido bastante. A crise que o setor viveu em 2005 mostrou que o Governo continua com dificuldades em disponibilizar os recursos no período correto para assegurar a garantia de preços. Além da dificuldade com as compras, houve também, impasse na realização dos leilões de opções.

Ficou evidente, pelo resultado obtido através do modelo de armazenamento que, o contrato privado de opção de venda é um instrumento de seguro de preços que pode ser complementado pelas compras do governo.

Os instrumentos de sustentação de preços para todo o mercado são as AGFs, pois, através desse instrumento o Governo é capaz de reduzir a oferta do mercado aumentando os preços no mercado e beneficiando todos os produtores do mercado. Mas, ao aumentar os preços no mercado esse instrumento acaba por beneficiar também os produtores dos outros países que produzem arroz para exportar ao Brasil. Quando essas importações entram no mercado brasileiro causam uma pressão nos preços para baixo, o que pode causar pressão dos produtores brasileiros sobre o Governo para assegurar mais garantia de preços. 


\section{Referências bibliográficas}

BARROS, G.S.A.C. Avaliação do Programa Brasileiro de Opções Agrícolas. Piracicaba: CEPEA, 2000. 53 p. Relatório de pesquisa apresentado à FAPESP.

BARROS, G.S.A.C. Economia da comercialização agrícola. Piracicaba: CEPEA, 2005. 384p. Disponível em: < http://www. cepea.esalq.usp. br > . Acesso em: 12 fev. 2005.

BARROS, G.S.A.C.; GUIMARÃES, V.D.A. Análise da eficácia da política de preços para arroz e milho por meio de um modelo de expectativas racionais. Revista de Economia e Sociologia Rural, Brasília, v. 36, n. 4, p. 113-133, 1998.

BRESSLER, R.G.; KING, R.A. Markets, prices and interregional trade. New York: Wiley, 1970. 426 p.

COMPANHIA NACIONAL DE ABASTECIMENTO. Armazenagem. Disponível em: < http//conab.gov.br > . Acesso em: 12 out. 2005a.

COMPANHIA NACIONAL DE ABASTECIMENTO. Conjunturas agropecuárias. Disponível em: < http//conab.gov.br > . Acesso em: 12 jul. 2005b.

COMPANHIA NACIONAL DE ABASTECIMENTO. Indicadores agropecuários. Disponível em: < http//conab.gov.br >. Acesso em: 12 jul. 2005c.

COMPANHIA NACIONAL DE ABASTECIMENTO. Safras. Disponível em: < http//conab.gov.br >. Acesso em: 5 jul. 2005d.

INSTITUTO BRASILEIRO DE GEOGRAFIA E ESTATÍSTICA - IBGE. Disponível em: < http://www.ibge.gov.br > . Acesso em: 31 out. 2005.

INSTITUTO DE PESQUISA ECONÔMICA APLICADA - IPEA. Preços. Disponível em: < http://www.ipeadata.gov.br > Acesso em: 5 out. 2005b.

REZENDE, G.C. Estado, macroeconomia e agricultura no Brasil. Porto Alegre: UFRGS/ IPEA, 2003. 246 p. 